\title{
Modification of Ti-6Al-4V alloy element and phase composition by compression plasma flows impact
}

\author{
N.N. Cherenda ${ }^{1,2)}$, A.V. Basalai, ${ }^{3)}$, V.I. Shymanski ${ }^{1,2)}$, V.V. Uglov ${ }^{1,2)}$, V.M. Astashynski ${ }^{4)}$, \\ A.M. Kuzmitski ${ }^{4)}$, A.P. Laskovnev ${ }^{5)}$
}

${ }^{1}$ Belarusian State University, Nezavisimosti ave., 4, Minsk 220030, Belarus

${ }^{2}$ National Research Nuclear Tomsk Polytechnic University, Lenin ave., 2a, Tomsk 634028, Russia

${ }^{3}$ Physical Technical Institute of the National Academy of Sciences of Belarus, Kuprevicha str. 10, Minsk 220141, Belarus

${ }^{4}$ A.V. Luikov Heat and Mass Transfer Institute, National Academy of Sciences of Belarus, P. Brovki str., 15, Minsk 220072, Belarus

${ }^{5}$ Presidium of the National Academy of Sciences of Belarus, Nezavisimosti ave., 66, Minsk 220072, Belarus

\begin{abstract}
Phase and element composition, microhardness of Ti-6Al-4V titanium alloy, Ti/Ti-6Al-4V and $\mathrm{Zr} / \mathrm{Ti}-6 \mathrm{Al}-4 \mathrm{~V}$ systems treated by compression plasma flows have been investigated in this work. $\mathrm{X}$-ray diffraction, scanning electron microscopy, energy-dispersion X-ray microanalysis and Vickers microhardness measurements were used for samples characterization. The findings showed that treatment of the "coating/titanium alloy" system by compression plasma flows allowed decreasing the toxic elements (Al, V) concentration in the surface layer of Ti-6Al-4V titanium alloy. The variation of the energy absorbed by the surface layer resulted in the change of the element concentration and the formation of a number of phases in the modified layer: a solid solution on the basis of $\alpha^{\prime}$ phase in Ti-6Al-4V and Ti/Ti-6Al-4V systems and $\beta$ phase in $\mathrm{Zr} / \mathrm{Ti}-6 \mathrm{Al}-4 \mathrm{~V}$ system. The formation of $\delta-\mathrm{TiN}_{\mathrm{x}}$ at the surface due to interaction of surface layer atoms with nitrogen atmosphere in the vacuum chamber was also found. The change of phase composition and quenching effects resulted in the microhardness increase.
\end{abstract}

Key words: titanium alloy, Ti-6Al-4V, compression plasma flow, phase and element composition, zirconium, alloying, microhardness. 


\section{Introduction}

Being a good material with a high specific strength-to-weight ratio and excellent corrosion resistance pure titanium has a limited practical application due to low mechanical, tribological properties, a high oxidation rate at elevated temperatures. This problem is usually solved by producing composite alloys with different additional elements. Al, Si, N, O, etc. are $\alpha-$ stabilizing elements which broaden the temperature range of the titanium $\alpha$-phase existence. Most of the transition metals like $\mathrm{Mo}, \mathrm{Nb}, \mathrm{V}, \mathrm{Cr}, \mathrm{Fe}$, etc. are $\beta$-stabilizing elements which, in contrast, broaden the temperature range of titanium $\beta$-phase. Titanium alloys based on a mixture of both low-temperature $(\alpha)$ and high-temperature $(\beta)$ phases and named $(\alpha+\beta)$-alloys are in greater demand in industry. It is explained by a wide range of alloys properties determined not only by alloying elements type, but also by the relation between the phases and alloy microstructure.

Ti-6Al-4V titanium alloy (Grade 5) is one of the most commonly used Ti-based alloys. It was designed for aerospace, marine, chemical, automotive industries. It possesses a unique combination of such properties as low density, good corrosion resistance and enhanced strength. Ti-6Al-4V is $(\alpha+\beta)$ alloy in which Al atoms (6 wt. \%) mainly form a solid solution on the basis of $\alpha$ phase while $\mathrm{V}$ atoms ( $4 \mathrm{wt}$. \%) form a solid solution on the basis of $\beta$ phase. Aluminum addition results in the strength increase whereas vanadium addition allows maintaining plasticity. Ti-6Al-4V alloy is also widely used in medicine as a material for dental and orthopedic implants production [1].

The main problem of the Ti-6Al-4V use in medicine is the presence of such toxic elements as $\mathrm{Al}$ and $\mathrm{V}[2,3]$. Their penetration into the body tissue is considered as an undesirable effect resulting in different diseases. Nowadays this problem is solved by the following ways: i) replacement of vanadium by other elements with lower toxicity preserving biocompatibility of the alloy (for example, synthesis of Ti-6Al-7Nb alloy); ii) modification of the Ti-6Al-4V alloy surface or deposition of protective coatings to prevent vanadium penetration into the tissue. The first of the mentioned approaches often requires using elements with a high cost. Thus modification of Ti-6Al-4V alloy is the most acceptable and actively developed method $[4,5]$. Usually, modification is aimed at producing a barrier sub-surface layer with a lower vanadium content. In this case such mechanical properties as hardness, strength, etc., should be similar to those of the unmodified alloy. This will prevent the formation of a high mechanical stress gradient in the surface layer that causes cracks formation and destruction of the implant. Another wide-spread technique of vanadium-tissue contact limitation is protective coating deposition on the surface of Ti-6Al-4V alloy, e.g. deposition of a coating based on 
transition metals nitrides [6] or a graphite coating [7]. In this case a thin coating serves as a barrier layer between the implant and the tissue.

Not only toxicity of alloying elements in Ti-6Al-4V alloy but also high elasticity moduli as compared to those of the bone tissue are disadvantages of the alloy limiting its application. From the point of view of elasticity moduli, $\beta$-phase with a bcc crystal structure is of greater interest. It has moduli less than those of $\alpha$-phase.

For improvement of Ti-6Al-4V alloy mechanical properties intense plastic deformation [8] as well as plasma surface nitriding [7] can be applied. Plasma treatment demonstrates the increase of titanium-based implants wear resistance [9]. Improved mechanical properties and wear resistance of Ti-6Al-4V alloy are also desirable to increase implants life-time.

High energy plasma flows as well as charged particles beams can be effectively used for surface layers structure and phase composition modification while preserving properties of the material in the bulk. The findings showed that compression plasma flows (CPF) generated by quasi-stationary plasma accelerators could be effectively used for modification of the material surface properties $[10,11]$. The main aims of the work are to decrease toxic elements concentration in the surface layer of Ti-6Al-4V alloy by means of additional biocompatible elements incorporation into the surface layer (CPF treatment of Ti/Ti-6Al-4V and Zr/Ti-6Al-4V systems), to investigate the treated systems phase composition (Ti-6Al-4V alloy, Ti/Ti-6Al-4V and $\mathrm{Zr} / \mathrm{Ti}-6 \mathrm{Al}-4 \mathrm{~V}$ ), to evaluate the treated systems mechanical properties (microhardness testing).

\section{Experimental}

The samples of Ti-6Al-4V titanium alloy (6.1 wt.\% of $\mathrm{Al}$ and $4.0 \mathrm{wt} \%$ of $\mathrm{V})$ were polished disks with a diameter of $10 \mathrm{~mm}$ and a thickness of $5 \mathrm{~mm}$. Some samples were directly treated by compression plasma flows (CPF) generated in the magneto-plasma compressor (MPC) of compact geometry. The discharge device of the MPC was made as a system of two coaxial electrodes, the central electrode being a cathode and six surrounding electrodes performing the function of the anode. The capacitive storage of $1200 \mathrm{mF}$ operated at the initial voltage of $4 \mathrm{kV}$ was used. The experiments were performed in the "residual gas" mode, i.e. the vacuum chamber was filled with the nitrogen gas at the pressure of $400 \mathrm{~Pa}$. The plasma flow parameters were the following: the pulse duration was $100 \mu \mathrm{s}$, the plasma velocity was $(5-6) \times 10^{6} \mathrm{~cm} / \mathrm{s}$, the electron concentration was $(4-7) \times 10^{17} \mathrm{~cm}^{-3}$, the plasma temperature was $2-3 \mathrm{eV}$. The distance between the electrodes and the treated surface of the samples changed from 8 to $14 \mathrm{~cm}$, which corresponded to the energy density of heat flux absorbed by the sample (Q) of 10 and $23 \mathrm{~J} / \mathrm{cm}^{2}$ 
per pulse, respectively (registered by calorimetric measurements). Treatment was carried out by three pulses at the interval of $\sim 5 \mathrm{~s}$.

The rest of the samples were subjected to combined treatment including the preliminary coating deposition followed by the CPF impact with the parameters mentioned above. Two groups of samples were prepared. The titanium coating with a thickness of $2 \mu \mathrm{m}$ was deposited on Ti-6Al-4V samples of the first group. Ti-6Al-4V samples of the second group were covered by zirconium with the same thickness of the coating. The coatings were deposited using the vacuum arc vapor deposition technique with the following operating parameters: the arc current was $100 \mathrm{~A}$, the negative bias voltage on the titanium substrates was $-120 \mathrm{~V}$, the deposition time was 10 minutes.

The phase composition of the modified layers in Ti-6Al-4V alloy was investigated by means of the X-ray diffraction (XRD) method with the Ultima IV RIGAKU diffractometer in Bragg-Brentano geometry with parallel beams in $\mathrm{Cu} \mathrm{K \alpha}$ radiation $(\lambda=0.15418 \mathrm{~nm})$. The analysis of surface and cross-section morphology was carried out by means of scanning-electron microscopy (SEM) using the LEO 1455 VP microscope. The element composition of the modified surface layers of the samples was determined by means of the energy dispersion X-ray microanalysis (EDX) using the Oxford X-ray detector. The mechanical properties of the modified surface layers were evaluated by means of microhardness measurements. Microhardness was measured by the Vickers diamond indentor under the load of $1.0 \mathrm{~N}$ using the MVD 402 Wilson Instruments equipment.

\section{Results and discussion}

CPF treatment resulted in the surface layer melting, homogenization of its structure and elements distribution (Fig. $1 \mathrm{a}, \mathrm{b}$ ). One can see that $\mathrm{V}$ atoms are more uniformly distributed in the modified layer in contrast to their distribution in the bulk while the character of $\mathrm{Al}$ atoms distribution has remained unchanged (Fig 1b). Element composition homogenization takes place during treatment due to the processes of convection mass transfer arising in the melt as a result of hydrodynamic instabilities development at the plasma-melt border, like Kelvin-Helmholtz and Rayleigh-Taylor instability $[12,13]$. This mechanism is also in charge of mixing in the "coating/substrate" system subjected to CPF treatment. The increase of energy absorbed by the surface led to the growth of the melted layer thickness from $\sim 20 \mu \mathrm{m}\left(10 \mathrm{~J} / \mathrm{cm}^{2}\right)$ to $\sim 24 \mu \mathrm{m}(23$ $\left.\mathrm{J} / \mathrm{cm}^{2}\right)$.

An insignificant decrease of Al and V concentration (measured by EDX analysis at the sample surface in the layer with a thickness of $\sim 1 \mu \mathrm{m}$ ) was found after CPF treatment of Ti-6Al4V alloy (Fig. 2). The change of energy absorbed by the surface does not influence the 
concentration of these alloying elements (within the limits of the measurement error). The addition of other elements to the surface layer of Ti-6Al-4V alloy by CPF treatment of Ti/Ti6Al-4V and $\mathrm{Zr}$ /Ti-6Al-4V systems allows decreasing $\mathrm{Al}$ and $\mathrm{V}$ atoms concentration to a greater extent (Fig. 2). At $10 \mathrm{~J} / \mathrm{cm}^{2} \mathrm{Al}$ concentration in the surface layer is about $3.8 \mathrm{wt} . \%$ and $\mathrm{V}$ concentration - 2.7 wt.\% for the system Ti/Ti-6Al-4V; 3.8 wt.\% (Al) and 2.8 wt.\% (V) for the system $\mathrm{Zr} / \mathrm{Ti}-6 \mathrm{Al}-4 \mathrm{~V}$. The increase of energy absorbed by the surface leads to the growth of $\mathrm{Al}$ and $\mathrm{V}$ atoms concentration. This regularity of the element composition change can be explained by diminishing an additional (coating) element concentration in the surface layer with the growth of Q.

CPF treatment of the "coating/substrate" system under certain regimes leads to the melting of the coating and surface layer of the substrate, convection mixing of the coating and substrate elements in the melt and subsequent crystallization under conditions of high-speed cooling. The concentration of the coating element in the mixed layer is mainly controlled by two processes. The first of them is redistribution of the coating element in the melt due the convection mass transfer mechanism [14]. The second process is erosion of the surface layer during plasma impact due to a radial hydrodynamic flow of the melt from the center to the edges of the sample under plasma flow pressure $[13,14]$. The increase of energy absorbed by the surface leads to the growth of the melted layer thickness and the increase of the surface erosion intensity, thus resulting in diminishing the coating element concentration. According to samples cross-section analysis the melted layer thickness changed from $\sim 18$ to $\sim 23 \mu \mathrm{m}$ in $\mathrm{Zr} / \mathrm{Ti}-6 \mathrm{Al}-4 \mathrm{~V}$ system and from $\sim 19$ to $\sim 24 \mu \mathrm{m}$ in Ti/Ti-6Al-4V with the growth of Q from 10 to $23 \mathrm{~J} / \mathrm{cm}^{2}$. The corresponding $\mathrm{Zr}$ concentration in the surface layer of $\mathrm{Zr} / \mathrm{Ti}-6 \mathrm{Al}-4 \mathrm{~V}$ system after treatment at the Q of 10, 14, and $23 \mathrm{~J} / \mathrm{cm}^{2}$ amounted to $20.6 \pm 0.9$ wt. \%, 19.5 \pm 0.9 wt. \% and 10,8 \pm 0.5 wt. \%, respectively. Thus one can see that CPF treatment of the "coating/substrate" system leads to the synthesis of the modified surface layer the concentration of alloying elements in which can be controlled by the treatment parameters and by the amount of the additional coating element (coating thickness).

The results of the Ti-6Al-4V phase composition analysis before and after CPF treatment are presented in Fig. 3. In the initial state the presence of $\mathrm{V}$ precipitates and $\beta$ phase was found. Plasma treatment led to dissolution of $\beta$ phase and a slight decrease of $\mathrm{V}$ diffraction line intensity. As a result the increase of the $\mathrm{V}$ atoms concentration in the substitution solid solution on the basis of $\alpha$ phase can take place. This supposition is confirmed by the shift of $\alpha$ phase diffraction peaks to the area of greater diffraction angles, which indicates that the $\alpha$ phase crystal lattice diminishes because the $\mathrm{V}$ atom radius is smaller than that of $\mathrm{Ti}$ atom (atomic radii: $\left.r_{\mathrm{Ti}}=0,147 \mathrm{~nm}, r_{\mathrm{Al}}=0,143 \mathrm{~nm}, r_{\mathrm{V}}=0,136 \mathrm{~nm}[15]\right) . \alpha$-Ti phase can solve up to $2.7 \mathrm{wt} . \%$ of $\mathrm{V}$ according to 
the binary Ti-V phase diagram [16]. The presence of $\mathrm{Al}$ atoms in $\alpha$-Ti lattice can diminish this value. Besides, the formation of martensitic $\alpha^{\prime}$ phase is observed. The diffraction peaks of this phase are close enough to the diffraction peaks of $\alpha$ phase and can be seen as "shoulders" on the left or right side of $\alpha$ phase diffraction peaks. The appearance of $\alpha^{\prime}$ phase is more clearly observed near the (102), (110) and (103) $\alpha$-Ti diffraction lines and as a separate diffraction line at $2 \theta=38.1-38.3$ degree. The same diffraction characteristics of the $\alpha^{\prime}$ phase were observed in [17]. $\alpha^{\prime}$ phase can be formed by martensitic transformation of $\beta$ phase in the local areas with an increased concentration of $\mathrm{V}$ atoms (greater than limit of $\mathrm{V}$ atoms solid solubility in $\alpha$ phase) during cooling. Greater concentration of $\mathrm{V}$ atoms leads to distortion of the hcp crystalline lattice that can be enhanced with the Q growth due to cooling speed increase. In particular, the lattice parameters of $\alpha^{\prime}$ phase change from the values of $a=0.294 \mathrm{~nm}$, $c=0.472 \mathrm{~nm}$ after CPF treatment at $\mathrm{Q}=10 \mathrm{~J} / \mathrm{cm}^{2}$ to the values of $a=0.296 \mathrm{~nm}$ and $c=0.470 \mathrm{~nm}$ after CPF treatment at $\mathrm{Q}=23 \mathrm{~J} / \mathrm{cm}^{2}$. One can see that $c$ lattice parameter of $\alpha^{\prime}$ phase in contrast to $a$ lattice parameter decreases with the absorbed energy density growth and becomes close to that of $\alpha$-Ti phase $(0.465 \mathrm{~nm})$ that almost does not depend on the $\mathrm{Q}$ value. These data show nonuniform deformation of the $\alpha^{\prime}$ crystal lattice. The Q growth also leads to the increase of $\alpha^{\prime}$ phase diffraction lines intensity indicating the growth of $\alpha^{\prime}$ phase content in the analyzed layer. The phase composition observed changes correlate with the data of elements distribution along the sample depth, in particular with homogeneous $\mathrm{V}$ atoms distribution in the melted layer. Such a kind of distribution assumes that V atoms are located in $\alpha$ and $\alpha^{\prime}$ phases or can form dispersed precipitates uniformly distributed in the remelted layer.

The interaction of the surface layer atoms with nitrogen atmosphere in the vacuum chamber led to the formation of $\delta-\mathrm{TiN}_{\mathrm{x}}$ (Fig. 3). $\delta$-TiN $\mathrm{x}$ can be formed at the surface of the melt at the stage of high-speed cooling. $\delta$-TiN $\mathrm{T}_{\mathrm{x}}$ possesses high crystallization temperature - up to $3290^{\circ} \mathrm{C}$ [18]. It can be the first phase in the system that crystallizes during cooling of the melt. Formed $\delta$-TiN $\mathrm{x}_{\mathrm{x}}$ precipitates will serve as crystallization centers at the surface, thus forming the first crystallization front distributing in the bulk of the sample. The second crystallization front distributing to the surface is initiated at the bottom of the melt. As a result, the formation of a thin surface layer with dendrites directed normally to the surface containing $\delta$-TiN $\mathrm{x}_{\mathrm{x}}$ occurred (Fig. 4). The formation of $\alpha_{\mathrm{N}}^{\prime}$ phase (interstitial solid solution on the basis of $\alpha-\operatorname{Ti}(\mathrm{Al}, \mathrm{V})$ phase) also could be expected [19]. It could be formed as a result of high-speed cooling of $\beta$ phase region under conditions when nitrogen content was too low to form $\delta$ - $\mathrm{TiN}_{\mathrm{x}}$. $\alpha_{\mathrm{N}}^{\prime}$ diffraction peaks can overlap with diffraction peaks of $\alpha^{\prime}-\mathrm{Ti}(\mathrm{Al}, \mathrm{V})$ phase.

Similar tendencies in phase composition changes are observed in the case of Ti/Ti-6Al4V and Zr/Ti-6Al-4V systems after CPF treatment (Fig. 5 and Fig. 6). The shift of the $\alpha$ phase diffraction lines to the area of greater diffraction angles occurs, which can be connected with 
incorporation of $\mathrm{V}$ atoms into the $\alpha$ phase crystal lattice. The disappearance of $\mathrm{V}$ diffraction lines after treatment was found for both systems. For Ti/Ti-6Al-4V system it can be explained by the increase of $\mathrm{Ti}$ atoms concentration and the decrease of $\mathrm{V}$ atoms concentration in the melted layer (Fig. 2). Therefore most of vanadium atoms (<2.7 wt.\%) dissolve inside $\alpha$ or $\alpha^{\prime}$ phase while the rest of vanadium atoms can form tiny disperse precipitates that cannot be revealed by XRD. The intensity of $\alpha^{\prime}$ phase diffraction peaks in this system is also less than the intensity of $\alpha^{\prime}$ phase diffraction peaks in Ti-6Al-4V alloy after CPF treatment.

$\mathrm{CPF}$ treatment of $\mathrm{Zr} / \mathrm{Ti}-6 \mathrm{Al}-4 \mathrm{~V}$ system resulted in the formation of $\beta$ phase (Fig. 6). The intensity of its diffraction lines diminishes with the growth of $\mathrm{Q}$, which correlates with the decrease of $\mathrm{Zr}$ content in the surface layer (Fig. 2). The diffraction peaks of $\beta$ phase are not seen as separate diffraction lines after treatment with $\mathrm{Q}=23 \mathrm{~J} / \mathrm{cm}^{2}$. Zirconium is known to be a neutral element in relation to $\beta \leftrightarrow \alpha$ phase transformation. It should form a solid solution with $\alpha$ phase at room temperature under equilibrium conditions. At the same time under conditions of high-speed cooling $\beta \rightarrow \alpha$ transformation can be realized not by diffusion but by shear in the $\beta$ phase crystal lattice. The traces of such shear martensitic transformation in the form of "needles" in the structure are well seen on the image of the melted layer cross-section (Fig 4a). This transformation can be inhibited if there are alloying elements in the $\beta$ phase crystal lattice. Elements with atomic radii significantly differ from those of Ti can cause additional tension of the crystalline lattice, thus, blocking shear $\beta \rightarrow \alpha$ transformation. The possibility of zirconium atoms influence on the $\beta \rightarrow \alpha$ transformation under conditions of high-speed cooling was confirmed by the data of Ref. [20]. In this work the formation of $\beta$ phase stabilized by $\mathrm{Zr}$ atoms in $\mathrm{Ti}-\mathrm{Zr}$ alloy after laser remelting was found. The shift of the $\beta$ phase diffraction lines to the area of smaller diffraction angles indicates that $\mathrm{Zr}$ atoms with a greater atomic radius $\left(\mathrm{r}_{\mathrm{Zr}}=0,160 \mathrm{~nm}\right)$ can be incorporated into the $\beta$ phase crystalline lattice (Fig. 6). $\mathrm{V}$ atoms can also completely dissolve inside $\beta$ phase, thus explaining the absence of $\mathrm{V}$ diffraction lines after CPF treatment (Fig. 6). Zr atoms can also take part in the formation of $\alpha^{\prime}$ phase (left "shoulder" of (110) $\alpha$ phase at $\sim 62^{\circ}$ ). The intensity of this line diminishes with the decrease of $\mathrm{Zr}$ concentration. According to the data obtained one can conclude that at the concentration of $\sim 20 \mathrm{wt} . \%$ zirconium can stabilize $\beta$ phase under these experimental conditions. More precise concentration value cannot be determined due to the fact that $\mathrm{Zr}$ atoms can form solid solution on the basis of both $\alpha$ and $\beta$ phases.

$\delta$ - $\mathrm{TiN}_{\mathrm{x}}$ formation in the surface layer was found for both systems (Fig. 7). Such a film can be an effective surface barrier preventing diffusion of toxic elements from Ti-6Al-4V implants to somatic tissues.

The observed changes of the surface layer phase and element composition does not worse its strength properties. The surface layer microhardness increased $\sim 1.3$ times (Fig. 8). For all 
treatment regimes microhardness changed within the limits of the measurement error, thus allowing one to assume that structure refinement and $\delta$ - $\mathrm{TiN}_{\mathrm{x}}$ formation on the surface could be the main factors (common for all treated systems) influencing microhardness value.

\section{Conclusions}

Thus one can see that the addition of the coating element to the surface layer of the substrate by CPF treatment of the "coating/Ti-6Al-4V" system can be effective in diminishing the substrate alloying elements concentration. CPF treatment of Ti/Ti-6Al-4V and Zr/Ti-6Al-4V systems at $\mathrm{Q}=10 \mathrm{~J} / \mathrm{cm}^{2}$ led to the decrease of $\mathrm{Al}$ and $\mathrm{V}$ concentration 1.6 and 1.4 times, respectively. Besides homogenization of $\mathrm{V}$ atoms distribution in the remelted layer was observed. The remelted layer thickness was up to $\sim 24 \mu \mathrm{m}$.

A high cooling rate during crystallization of the melt in Ti-6Al-4V and Ti/Ti-6Al-4V system provided decomposition of $\beta$-Ti phase into $\alpha-\mathrm{Ti}(\mathrm{V}, \mathrm{Al})$ and $\alpha$ '-Ti(V,Al) phases. The formation of $\beta$ phase stabilized by $\mathrm{Zr}$ atoms was observed in $\mathrm{Zr} / \mathrm{Ti}-6 \mathrm{Al}-4 \mathrm{~V}$ system. The increase of energy absorbed by the surface layer led to diminishing $\mathrm{Zr}$ concentration and $\beta$ phase content in the alloyed layer. The estimated value of $\mathrm{Zr}$ concentration necessary for $\beta$ phase stabilization is $\sim 20 \mathrm{wt} . \%$. The interaction of the surface layer atoms with nitrogen atmosphere in the vacuum chamber led to the formation of $\delta$-TiN $\mathrm{N}_{\mathrm{x}}$ nitride for all treated systems.

The surface layer microhardness increased $~ 1.3$ times inspite of $\mathrm{Al}$ and $\mathrm{V}$ concentration decrease in the surface layer. Structure refinement and $\delta-\mathrm{TiN}_{\mathrm{x}}$ formation on the surface could be the main reasons for the microhardness growth.

\section{Acknowledgements}

The experimental investigations were partially carried out at Tomsk Polytechnic University within the framework of Tomsk Polytechnic University Competitiveness Enhancement Program grant. 


\section{References}

1. K.S. Katti. Biomaterials in total joint replacement // Colloids and Surfaces B: Biointerfaces. - 2004. - Vol. 39, № 3. - P. 133-142.

2. M.A. Khan, R.L. Williams, D.F. Williams. The corrosion behaviour of Ti6Al-4V, Ti-6Al-7Nb and Ti-13Nb-13Zr in protein solutions // Biomaterials. - 1999. - Vol. 20. - P. 631-637.

3. Y. Okazaki, E. Shimura. Corrosion resistance, mechanical properties, corrosion fatigue strength and biocompatibility of new $\mathrm{Ti}$ alloys without $\mathrm{V}$ for medical implants // Proc. World conf. on titanium, 9th. - St. Peterburg. - 1999. - P. $1135-1150$.

4. O.I. Yaskiv, I.M. Pohrelyuk, V.M. Fedirko, D.B. Lee, O.V. Tkachuk. Formation of oxynitrides on titanium alloys by gas diffusion treatment // Thin Solid Films. - 2011. Vol. 519. - P. 6508-6514.

5. C.J. Tsai, L.M. Wang. Improved mechanical properties of Ti-6Al-4V alloy by electron beam welding process plus annealing treatments and its microstructural evolution // Materials and Design. - 2014. - Vol. 60. - P. 587-598.

6. L. Jin, A.R. Riahi, K. Farokhzadeh, A. Edrisy. Investigation on interfacial adhesion of Ti6Al-4V/nitride coatings // Surface and Coatings Technology. - 2014. - Vol. 260. - P. 155-167.

7. M. Sylvestre, H. Zaidi, J.P. Riviere, D. Eyidi, F. Doyen. Fretting contact study of Ti-6Al$4 \mathrm{~V} /$ graphite couples in a dry shaft/bearing contact with thrust: Influence of plasma nitriding of the titanium alloy // Surface and Coatings Technology. - 2010. - Vol. 205. P. 1374-1380.

8. S.V. Zherebtsov, G.A. Salishchev, R.M. Galeyev, O.R. Valiakhmetov, S.Yu. Mironov, S.L. Semiatin. Production of submicrocrystalline structure in large-scale Ti-6Al-4V billet by warm severe deformation processing // Scripta Materialia. - 2004. - Vol. 51. - P. 1147-1151.

9. G. Cassar, A. Matthews, A. Leyland. Triode plasma diffusion treatment of titanium alloys // Surface and Coatings Technology. - 2012. - Vol. 212. - P. 20-31.

10. N.N. Cherenda, V.V. Uglov, V.M. Anishchik, A.K. Stalmashenok, V.M. Astashynski, A.M. Kuzmickii, A.V. Punko, G. Thorwath, B. Stritzker. Modification of high-speed steels by nitrogen compression plasma flow: Structure, element composition, tribological properties // Surface and Coatings Technology. - 2006. - Vol. 200. - P. 5334-5342. 
11. V.I. Shymanski, N.N. Cherenda, V.V. Uglov, V.M. Astashynski, A.M. Kuzmitski. Structure and phase composition of $\mathrm{Nb} / \mathrm{Ti}$ system subjected to compression plasma flows impact // Surface and Coatings Technology. - 2015. - Vol. 278. - P. 183-189.

12. G. Miloshevsky, A. Hassanein. Effects of plasma flow velocity on melt-layer splashing and erosion during plasma instabilities // Nuclear Fusion. - 2014. -Vol. 54. - P. 033008.

13. B. Bazylev, G. Janeschitz, I. Landman, S. Pestchanyi, A. Loarte, G. Federici, M. Merola, J. Linke, T. Hirai, A. Zhitlukhin, V. Podkovyrov, N. Klimov. Behaviour of melted tungsten plasma facing components under ITER-like transient heat loads. Simulations and experiments // Fusion Engineering and Design. - 2008. - Vol. 83. - P. 1077-1081.

14. N.N. Cherenda, A.P. Laskovnev, A.V. Basalai, V.V. Uglov, V.M. Astashynski, A.M. Kuzmitski. Erosion of Materials under the Effect of Compression Plasma Flows // Inorganic Materials: Applied Research. - 2015. - Vol. 6, No. 2. - P. 114-120.

15. Smithells Metals Reference Book (Seventh edition). Oxford, 1992.

16. Phase diagrams of binary metal systems. Ed. N.P.Lyakishev. Moscow. Mashinostroenie. 2000, Vol.3, Part 1, 872 p.

17. H. Matsumoto, H. Yoneda, K. Sato, S. Kurosu, E. Maire, D. Fabregue, T.J. Konno, A. Chiba. Room-temperature ductility of Ti-6Al-4V alloy with $\alpha^{\prime}$ martensite microstructure // materials Science and Engineering A. - 2011. - Vol. 528. - P. 1512-1520.

18. Phase diagrams of binary metal systems. Ed. N.P.Lyakishev. Moscow. Mashinostroenie. 2000, Vol.3, Part 2, 448 p.

19. N.N. Cherenda, V.I. Shimanskii, V.V. Uglov, V.M. Astashinskii, V.A. Ukhov. Nitriding of Steel and Titanium Surface Layers under the Action of Compression Plasma Flows // Journal of Surface Investigation. X-ray, Synchrotron and Neutron Techniques. - 2012. Vol. 6, No. 2. - P. 319-325.

20. Y.Yao, X. Li, Y.Y. Wang, W. Zhao, G. Li, R.P. Liu. Microstructural evolution and mechanical properties of $\mathrm{Ti}-\mathrm{Zr}$ beta titanium alloy after laser surface remelting // Journal of Alloys and Compounds. - 2014. - № 583. - P. 43-47. 


\section{Figure captions}

Fig. 1. Cross-section SEM-image (a) and elements distribution along the AA' line of Ti-6Al-4V sample treated by compression plasma flows at $Q=10 \mathrm{~J} / \mathrm{cm}^{2}$

Fig. 2. $\mathrm{Al}$ and $\mathrm{V}$ concentrations in Ti-6Al-4V (1), Ti/Ti-6Al-4V (2) and Zr/Ti-6Al-4V (3) systems after compression plasma flows treatment at different Q.

Fig 3. XRD patterns of Ti-6Al-4V samples treated by compression plasma flows (1 - initial state, $2-\mathrm{Q}=10 \mathrm{~J} / \mathrm{cm}^{2}, 3-\mathrm{Q}=23 \mathrm{~J} / \mathrm{cm}^{2}$ ). Angle positions of $\alpha$-Ti standard diffraction lines (card file \# 00-044-1294) are indicated by dotted lines. Angle positions of $\alpha^{\prime}$ diffraction lines are indicated by *

Fig. 4. Cross-section SEM-image (a) and elements distribution along the AA' line of Ti-6Al-4V sample treated by compression plasma flows at $Q=23 \mathrm{~J} / \mathrm{cm}^{2}$

Fig 5. XRD patterns of Ti/Ti-6Al-4V samples treated by compression plasma flows (1 - initial state, $2-\mathrm{Q}=10 \mathrm{~J} / \mathrm{cm}^{2}, 3-\mathrm{Q}=23 \mathrm{~J} / \mathrm{cm}^{2}$ ). Angle positions of $\alpha$-Ti standard diffraction lines (card file \# 00-044-1294) are indicated by dotted lines.

Fig. 6. XRD patterns of $\mathrm{Zr} / \mathrm{Ti}-6 \mathrm{Al}-4 \mathrm{~V}$ samples treated by compression plasma flows (1 - initial state, $2-\mathrm{Q}=10 \mathrm{~J} / \mathrm{cm}^{2}, 3-\mathrm{Q}=14 \mathrm{~J} / \mathrm{cm}^{2}, 4-\mathrm{Q}=23 \mathrm{~J} / \mathrm{cm}^{2}$ ). Angle positions of $\alpha$-Ti standard diffraction lines (card file \# 00-044-1294) are indicated by dotted lines.

Fig. 7. XRD pattern (X-ray grazing incidence of $3^{\circ}$ ) of $\mathrm{Zr} / \mathrm{Ti}-6 \mathrm{Al}-4 \mathrm{~V}$ sample treated by compression plasma flows at $\mathrm{Q}=23 \mathrm{~J} / \mathrm{cm}^{2}$.

Fig. 8. Microhardness of Ti-6Al-4V alloy, Ti/Ti-6Al-4V and $\mathrm{Zr} / \mathrm{Ti}-6 \mathrm{Al}-4 \mathrm{~V}$ systems after compression plasma flows treatment at $\mathrm{Q}=14 \mathrm{~J} / \mathrm{cm}^{2}$. 
Fig. 1

a)

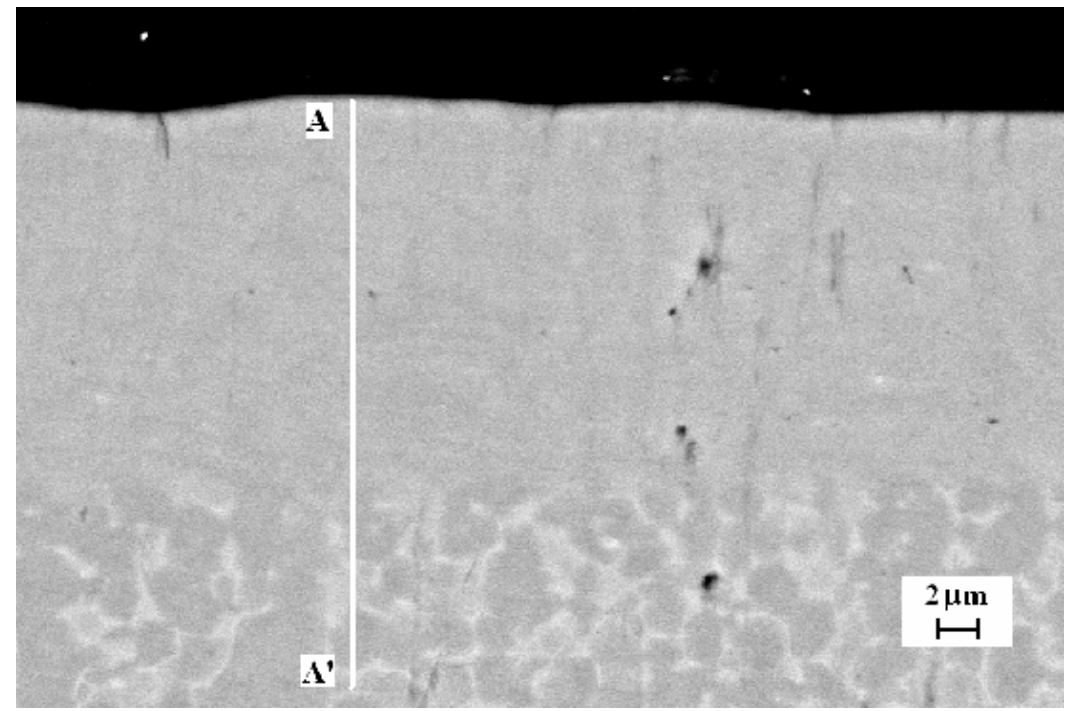

b)

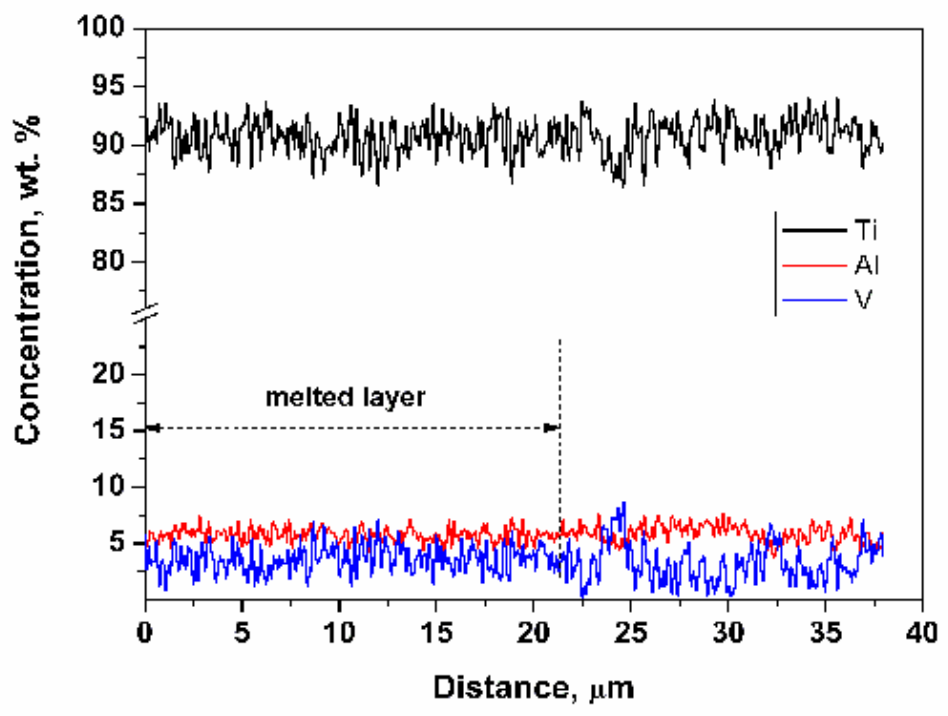


Fig 2

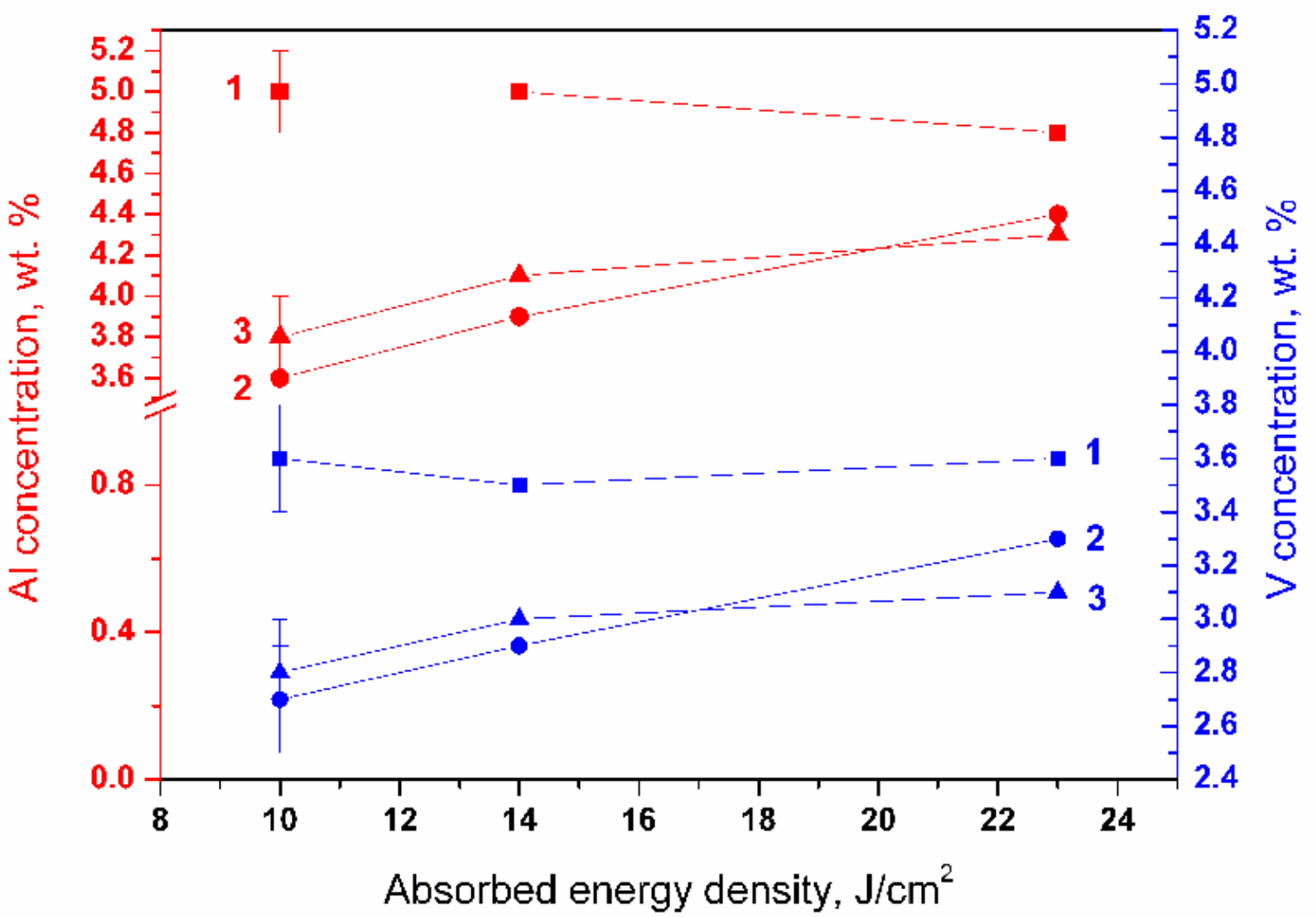


Fig 3

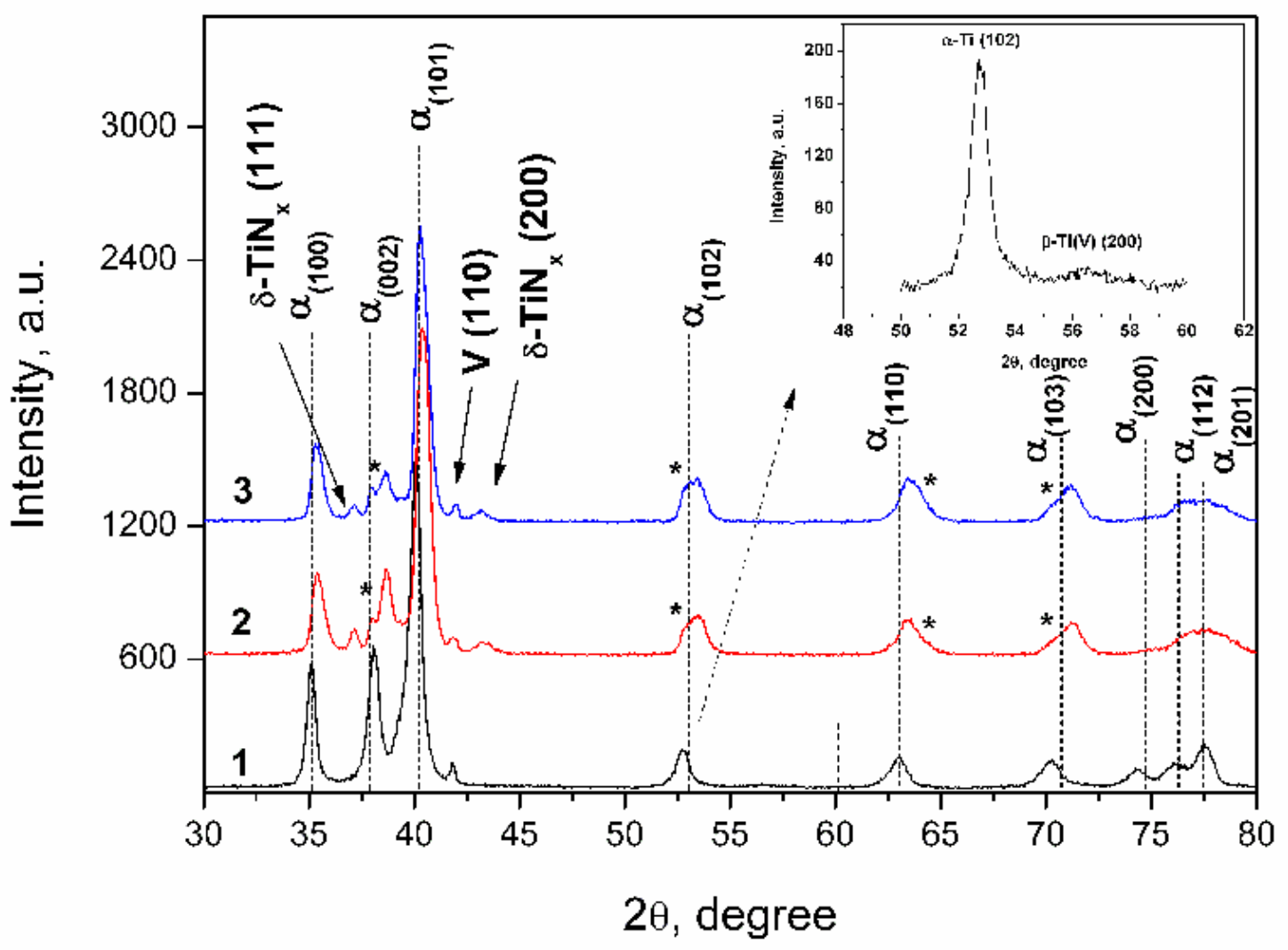


Fig 4

a)

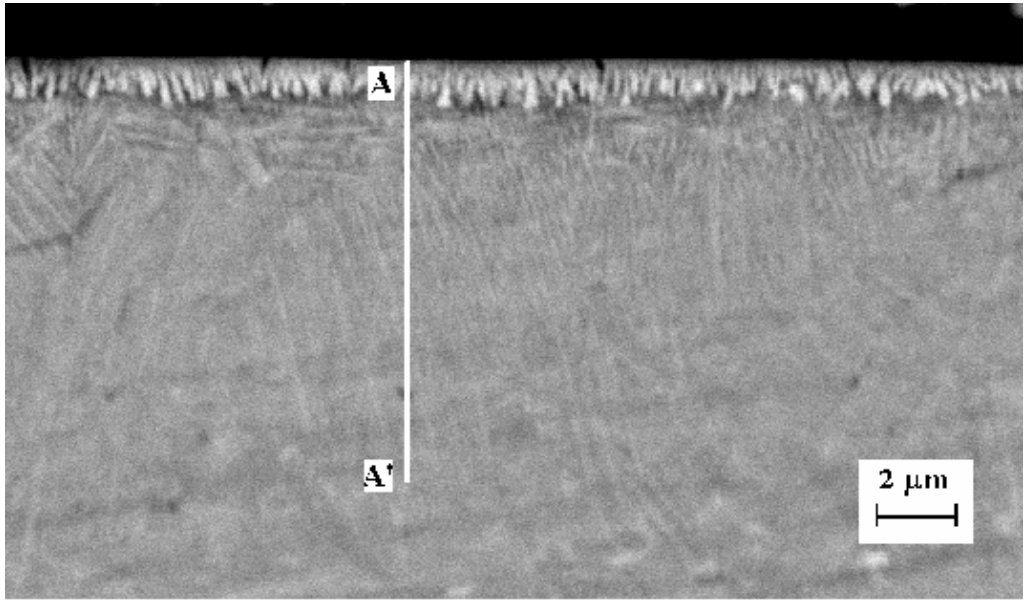

b)

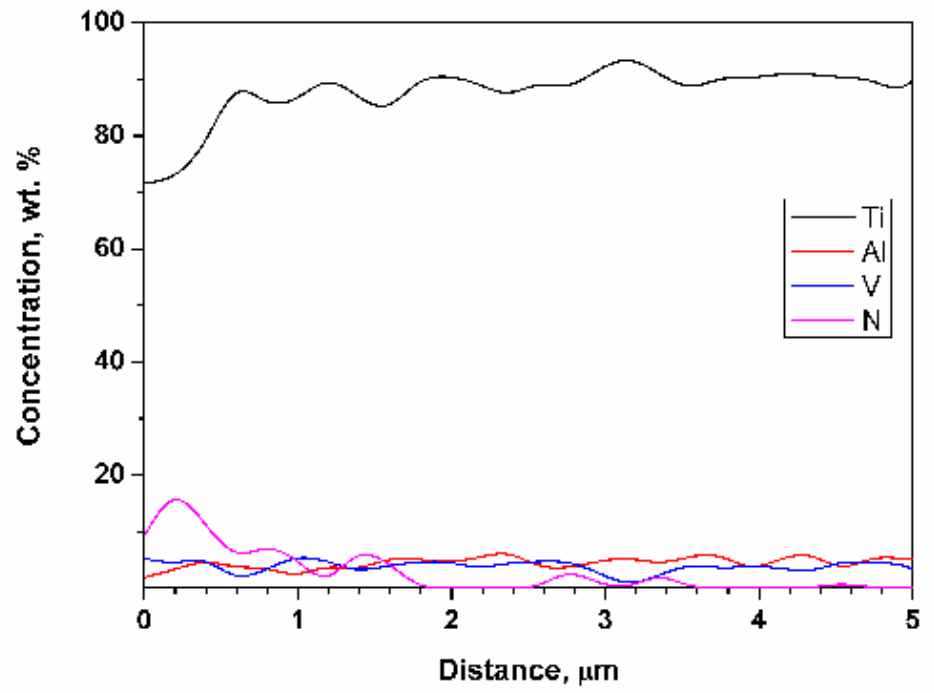


Fig 5

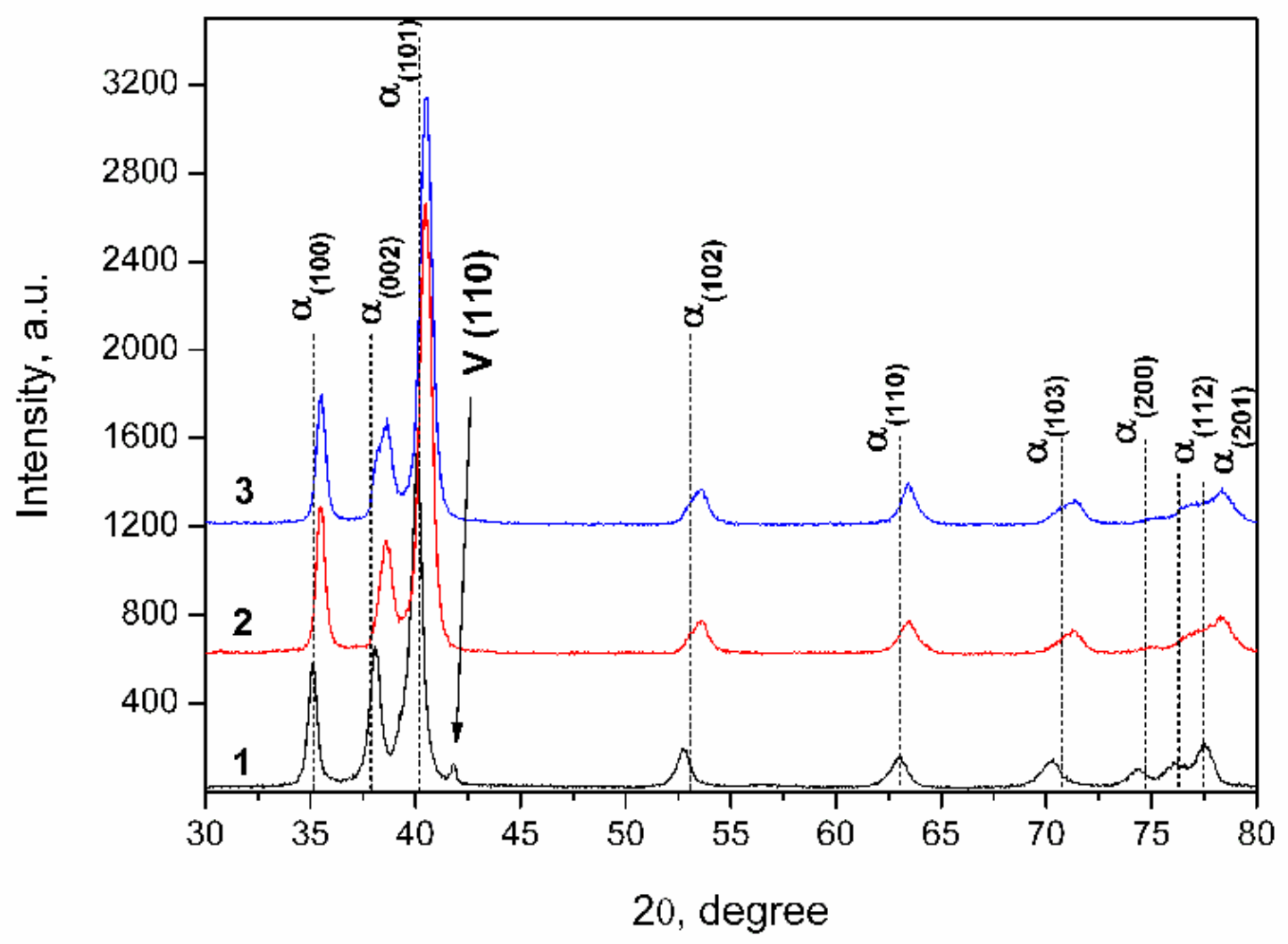


Fig 6

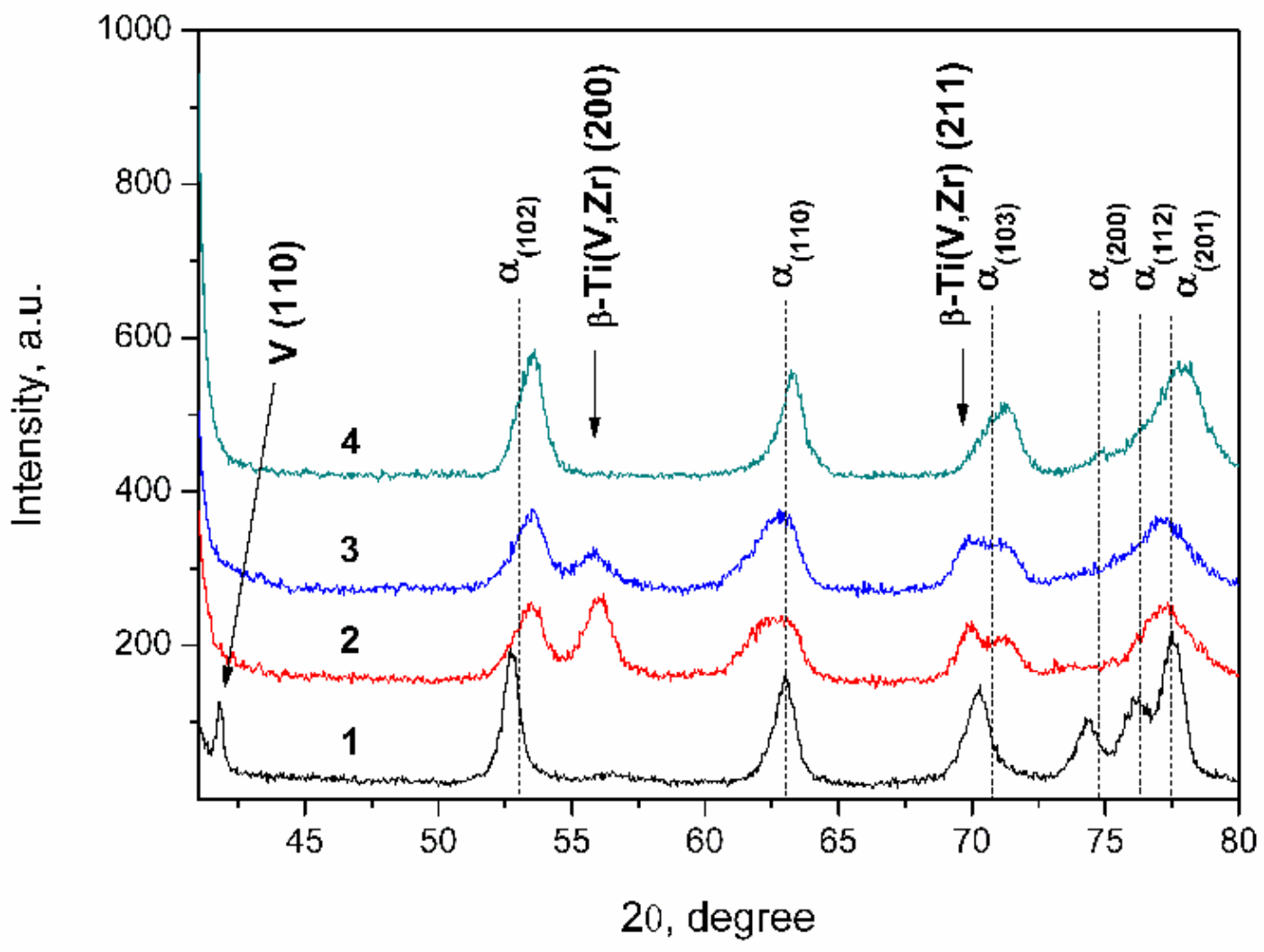


Fig 7

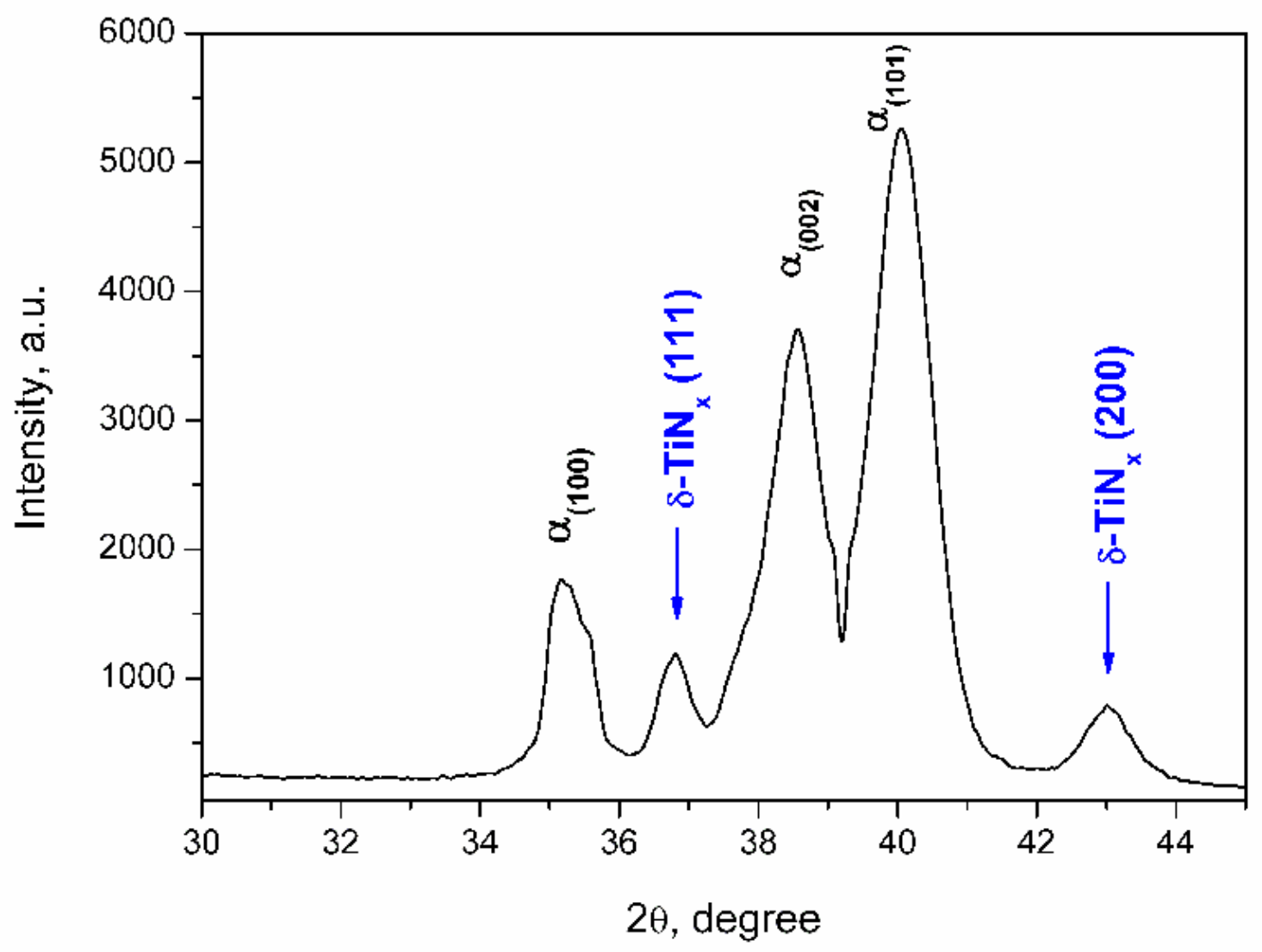


Fig 8

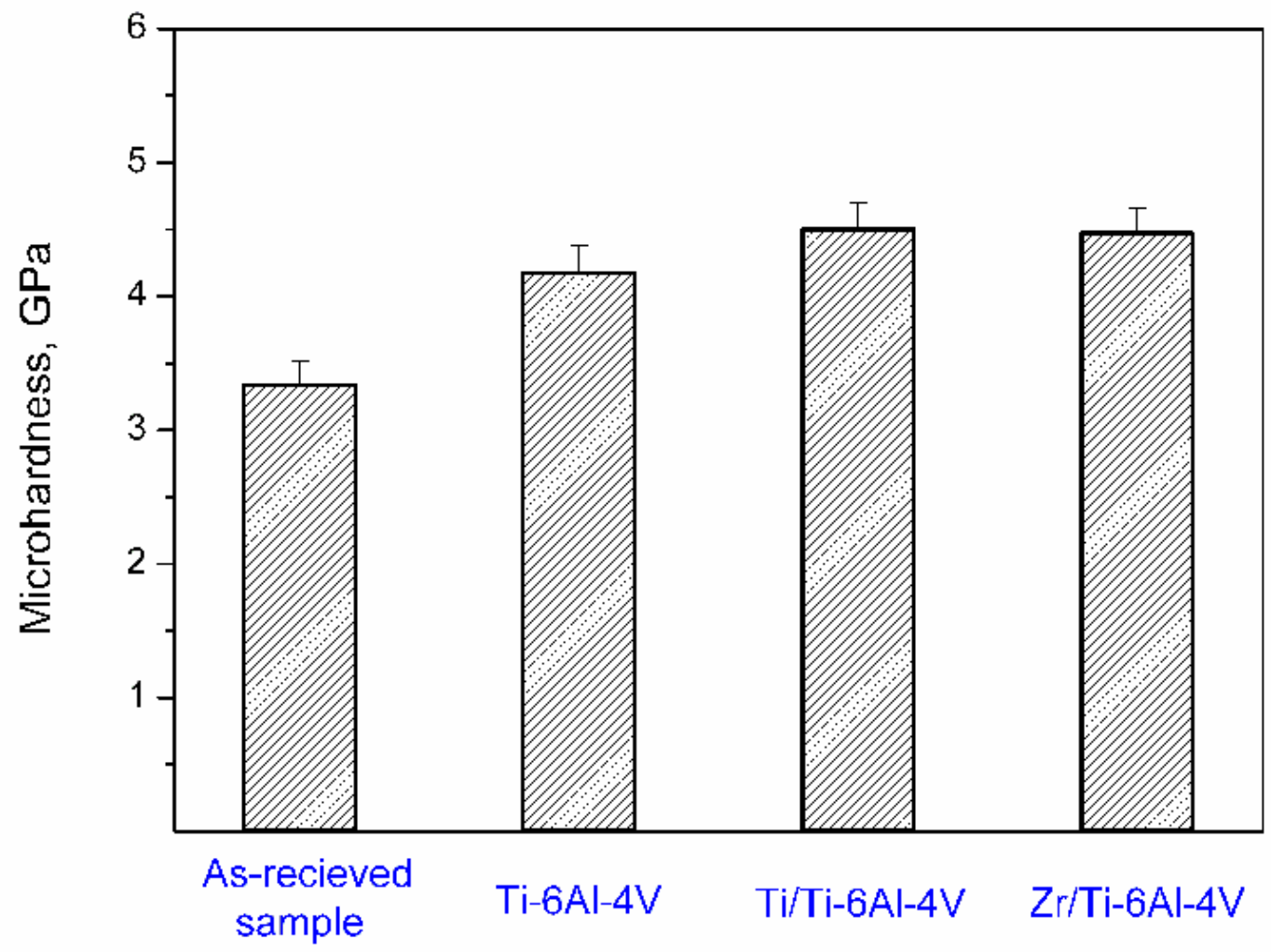

